\title{
Psychometric quality of family adaptability and cohesion evaluation scale IV by latent class analysis; quantitative study on the elderly in Romania
}

\section{DOI: http://doi.org/10.26758/9.1.10}

Cornelia RADA

"Francisc I. Rainer" Anthropology Institute of the Romanian Academy

Address correspondence to: Cornelia Rada, "Francisc I. Rainer" Anthropology Institute of the Romanian Academy, Academy House, 13 September Avenue, $5^{\text {th }}$ District, Bucharest, Romania, Zip Code 050711, Ph.: +40-728-824-852; Fax +40-21-317-50-72;

E-mail: corneliarada@yahoo.com

\begin{abstract}
Objective. The aim of this study is to show the strengths of Romanian version of the Family Adaptability and Cohesion Evaluation Scale IV (FACES IV) on a sample of subjects without apparent problems and to assess the cohesion and flexibility of the FACES IV according to gender, age and place of residence. FACES is useful in clinical evaluations and assessments of marital and family therapeutic interventions, in research highlighting changes within family life cycles.

Material and method. A cross-sectional study on 601 subjects aged between 55 and 93 years, using Latent Class Analysis with 2 models: clusters and discrete factors.

Results. The Cronbach's alpha coefficient was from .55 for the Chaotic scale to .80 for the Cohesion scale and over .91 for the Communication and Satisfaction scales. Like the author of the instrument the study identified 6 types of families. About three quarters described family as balanced or midrange. The Pearson Chi-Square showed that there was a statistically significant difference in Circumplex Total Ratio score between the different residence places $(p<0.05)$, the share of the unhealthy family system being higher in the rural area compared with the urban environment. No significant differences in Circumplex Total Ratio scores between genders or age groups were observed.

Conclusion. The absence of significant differences by gender or age group indicated that ageing requires abandoning the interactional competitive model and a good behavior in adaptability and cohesion. The Chaotic concept in the Romanian ex-Communist cultural space could be clarified by interviews.
\end{abstract}

Keywords: FACES IV, cohesion, flexibility, elderly, family life cycles.

\section{Introduction}

The Family Adaptability and Cohesion Evaluation Scale (FACES) initiated in 1979 (Olson, Sprenkle and Russell, 1979) is useful in clinical evaluations and assessments of marital and family therapeutic interventions. The FACES or the Circumplex Model of Marital and Family Systems conceptualizes the family using the cohesion, flexibility, and communication dimensions.

In the most recent version of the family evaluation scale, FACES IV, there are 25 types of families, and each is represented as a small square framed within a large square. Family members are typically envisioned as being connected by an emotional bond, referred to as cohesion. Flexibility (Adaptability) is defined as the quality and expression of leadership and 
organization, role relationships, and rules and negotiation within relationships. Similar to FACES II and FACES III, in FACES IV, there are 2 balanced scales that assess balanced family cohesion and balanced family flexibility. FACES IV also contains 4 unbalanced scales that assess the high and low extremes of cohesion and flexibility: 2 unbalanced scales for cohesion, which include disengaged and enmeshed, and 2 unbalanced scales for flexibility, which include rigid and chaotic (Olson and Gorall, 2006; Olson, 2011).

FACES IV is composed of 42 items where the participants rate their degree of agreement on a 5-point scale ranging from 1 to 5 (1, totally disagree; 5, totally agree). The scores showed adequate internal consistency values in the original American version (enmeshed, .77; disengaged, .87; balanced cohesion, .89; chaotic, .86; balanced flexibility, .84; rigid $=.82$ ) (Olson, 2011).

FACES IV scale performs well in the assessment of families before and after therapy, for example, on alcoholic families (Margasiński, 2014).

FACES IV can identify the adaptive resources of the families that face crisis or health issues. For instance, the assessment with FACES IV of married couples where the other was schizophrenic revealed surprisingly the fact that more than three fourths described their family as balanced (Carvalho et al., 2014). Another example on Clinical and Normal Italian Families has shown that "a large percentage of health-oriented members, in normal and clinical population, underlined the family's ability to respond to difficulties and painful situations, such as the presence of a disorder in one of its member and suggests avoiding the direct association between the presence of a disorder and the presence of dysfunction in the family" (Visani et al., 2017).

The diagnosis of a chronic illness and the necessary treatment require the family to move from an Enmeshed model to a more rigid one, as is the case of families who have a child suffering from cancer (Marsac and Alderfer, 2011).

During the life cycles, the individuals can decide to move from a more relaxed model to a more rigid one, as in the case of the impact of the new parental status on career involvement an aspect that FACES can identify (Rada and Olson, 2016).

Within Europe, FACES IV was adapted and validated in Hungary (Mirnics et al., 2010), Italy (Baiocco et al., 2013; Di Nuovo, Loriedo and Visani, 2013), Greece (Koutra et al., 2013), Spain (Rivero, Martínez-Pampliega and Olson, 2010), and Portugal (Hugo, Peixoto and Gouveia-Pereira, 2017).

Other authors have also been concerned with updating FACES IV. The most recent update of FACES IV on families without apparent problemsfrom Italy showed that the instrument has a good power (Loriedo, Visani and Di Nuovo, 2017).

The first step in the Romanian Validation of Family Adaptability and Cohesion Scale IV (FACES IV) and evaluation of Family Communication and Family Satisfaction scales were done on the basis of a quantitative cross-sectional study conducted between 2013 and 2014 on a total of 1,359 young people aged between 18 and 30 years old (Rada, 2018).

The scales were independently translated from English into Romanian by 2 psychologists who were native Romanian speakers with high English proficiencies. When the translations were different, a third specialist was consulted. The procedure was in compliance with Translation Guidelines provided by Life Innovation (Olson, 2010b).

The main limits of that study were the fact that it included only a young age segment of population and the sample had an unbalanced structure from the point of view of marital status.

At the same time, a lower internal consistency has been identified at some scales. This study was launched to overcome these impediments and to make a final form of the Romanian FACES IV version.

This article on FACES IV in Romania is useful for allowing intercultural comparisons with other studies that have validated and used this tool in other countries. The model can surprise family dynamics, becomes more obvious during the transitions within life cycles, such 
as the emergence of the parent status after childbirth, the retirement, or as a result of an unpleasant, stress-generating event, such as illness or accident. FACES IV is useful for clinical evaluation, treatment, as well as to evaluate the efficacy of marital and family therapeutic intervention.

\section{Material and methods}

\section{Design and sampling}

This article is based on a quantitative cross-sectional study carried out between 2016 and 2017 on a total of 601 patients who were treated within the "Ana Aslan" National Institute of Gerontology and Geriatrics aged between 55 and 93 years, without apparent problems regarding family. People under family psychotherapy, under the age of 55 years, non-cooperative people, individuals with strong auditory or visual sensory deficits, with severe cognitive deficits, with disorders accompanied by psychotic elements with serious somatic pathology have not been selected for this study. Table 1 displays the basic sociodemographic variables of the sample population.

Table 1. Sociodemographic and Family Characteristics of the Participants

\begin{tabular}{|c|c|c|}
\hline Sociodemographic data & $\mathrm{N}$ & $\%$ \\
\hline \multicolumn{3}{|l|}{ Gender } \\
\hline Female & 492 & 81.9 \\
\hline Male & 109 & 18.1 \\
\hline \multicolumn{3}{|l|}{ Age groups (years) } \\
\hline $55-64$ & 224 & 37.3 \\
\hline $65-74$ & 272 & 45.3 \\
\hline $75-84+$ & 105 & 17.4 \\
\hline \multicolumn{3}{|l|}{ Place of residence } \\
\hline Urban & 445 & 74.0 \\
\hline Rural & 156 & 26.0 \\
\hline \multicolumn{3}{|l|}{ Marital status } \\
\hline Married & 318 & 52.9 \\
\hline Widowed & 202 & 33.6 \\
\hline Divorced & 55 & 9.2 \\
\hline Consensual union over 1 year & 19 & 3.2 \\
\hline Unmarried (single) & 7 & 1.2 \\
\hline \multicolumn{3}{|l|}{ Employment status } \\
\hline Not working (pensioners (retired), housewives) & 574 & 95.5 \\
\hline Working & 27 & 4.5 \\
\hline \multicolumn{3}{|l|}{ Education } \\
\hline Elementary/high school (up to 12 years of school) & 167 & 27.8 \\
\hline Lyceum/vocational school/school of foreman in a profession & 305 & 50.7 \\
\hline
\end{tabular}




\begin{tabular}{|l|c|c|}
\hline Sociodemographic data & $\mathrm{N}$ & $\%$ \\
\hline University degree & 129 & 21.5 \\
\hline \multicolumn{3}{|c|}{ Children in the family } \\
\hline 0 & 57 & 9.5 \\
\hline $1+$ & 544 & 90.5 \\
\hline \multicolumn{3}{|c|}{ The number of family members living with the respondent including himself } \\
\hline 1 & 175 & 29.1 \\
\hline 2 & 278 & 46.3 \\
\hline 3 & 58 & 9.7 \\
\hline 4 & 34 & 5.7 \\
\hline $5+$ & 56 & 9.2 \\
\hline
\end{tabular}

\section{Measurements, questionnaire design}

Depending on the doctor's recommendation and diagnosis, up to 15 blood tests have been performed (usual clinical parameters) on the patients. Several questionnaires on personality, depression, memory, and quality of life have been applied. An Omnibus-type questionnaire was used, with 36 items that collected sociodemographic data, data on behaviors harmful for health, and opinions and attitudes relevant to the health of the elderly and the FACES IV Package, which contains6 scales from the Family Adaptability and Cohesion Scale IV (FACES IV) with 42 items and 2 scales on the Family Communication and Family Satisfaction, each with 10 items (Olson, 2010a).

The questionnaires were completed in the form of a face-to-face interview with each individual patient conducted by a psychologist. The response rate was $100 \%$. Care and sensitivity were applied at all times when dealing with the respondents.

The aim of this study is to finalize the development and testing of the psychometric quality of Romanian version of the Family Adaptability and Cohesion Evaluation Scale IV (FACES IV) on a non-clinic sample of elderly subjects and to assess the cohesion and flexibility of the FACES IV according to gender, age, and marital status.

In the first Romanian study on FACES IV Package, the Flexibility, Enmeshed, Rigid scales had relatively low consistency, with Cronbach's alpha of $0.69,0.61,0.66$, respectively and low on Chaotic scale, with Cronbach's alpha of 0.53 (Rada, 2018). For this reason, focus groups were organized, aiming to compare the family category to which they belong, in accordance with FACES IV where the family type results were based on the face-to-face discussions. These indepth interviews showed the necessity of rephrasing more clearly and more concise the following items $2,5,10,11,14,16,22,23,26,28,29,34,35,38,40$, and 41 (Table 2).

Table 2. Original and reworded items

\begin{tabular}{|l|l|l|}
\hline $\begin{array}{l}\text { Item } \\
\text { nr. }\end{array}$ & Original items & Reworded items \\
\hline 2 & $\begin{array}{l}\text { Our family tries new ways of dealing } \\
\text { with problems. }\end{array}$ & $\begin{array}{l}\text { Our family looking (try) new ways to solve } \\
\text { problems }\end{array}$ \\
\hline 4 & $\begin{array}{l}\text { There are strict consequences for } \\
\text { breaking the rules in our family }\end{array}$ & $\begin{array}{l}\text { For breaking the rules in our family applies } \\
\text { strict penalties }\end{array}$ \\
\hline 10 & $\begin{array}{l}\text { Family members feel pressured to } \\
\text { spend most free time together. }\end{array}$ & $\begin{array}{l}\text { Family members feel compelled to spend } \\
\text { most of their leisure time together }\end{array}$ \\
\hline
\end{tabular}




\begin{tabular}{|c|c|c|}
\hline $\begin{array}{l}\text { Item } \\
\text { nr. }\end{array}$ & Original items & Reworded items \\
\hline 11 & $\begin{array}{l}\text { There are clear consequences when a } \\
\text { family member does something wrong. }\end{array}$ & $\begin{array}{l}\text { There are clear sanctions when a family } \\
\text { member does something wrong }\end{array}$ \\
\hline 14 & Discipline is fair in our family. & $\begin{array}{l}\text { In our family, discipline is based on justice, } \\
\text { equity }\end{array}$ \\
\hline 16 & $\begin{array}{l}\text { Family members are too dependent on } \\
\text { each other }\end{array}$ & $\begin{array}{l}\text { We are too dependent on each other in the } \\
\text { family }\end{array}$ \\
\hline 22 & $\begin{array}{l}\text { Family members have little need for } \\
\text { friends outside the family }\end{array}$ & We do not need friends outside the family \\
\hline 23 & Our family is highly organized. & Our family is extremely organized \\
\hline 26 & $\begin{array}{l}\text { We shift household responsibilities } \\
\text { from person to person }\end{array}$ & $\begin{array}{l}\text { We can change household responsibilities } \\
\text { from one person to another }\end{array}$ \\
\hline 28 & We feel too connected to each other & We are too connected, bound to each other \\
\hline 29 & $\begin{array}{l}\text { Our family becomes frustrated when } \\
\text { there is a change in our plans or } \\
\text { routines }\end{array}$ & $\begin{array}{l}\text { Our family becomes frustrated when there is } \\
\text { a change in her plans or her usual schedule }\end{array}$ \\
\hline 34 & $\begin{array}{l}\text { We resent family members doing } \\
\text { things outside the family }\end{array}$ & $\begin{array}{l}\text { We do not like when family members are } \\
\text { always doing things outside the family }\end{array}$ \\
\hline 35 & $\begin{array}{l}\text { It is important to follow the rules in } \\
\text { our family }\end{array}$ & $\begin{array}{l}\text { It is especially important to respect the rules } \\
\text { in our family }\end{array}$ \\
\hline 38 & When problems arise, we compromise & $\begin{array}{l}\text { When new problems arise, we can make } \\
\text { agreements based on reciprocal yields, a } \\
\text { compromise }\end{array}$ \\
\hline 40 & $\begin{array}{l}\text { Family members feel guilty if they } \\
\text { want to spend time away from the } \\
\text { family. }\end{array}$ & $\begin{array}{l}\text { Family members feel guilty when they want } \\
\text { to spend separate family time }\end{array}$ \\
\hline 41 & $\begin{array}{l}\text { Once a decision is made, it is very } \\
\text { difficult to modify that decision. }\end{array}$ & $\begin{array}{l}\text { Once a decision is made, it is very difficult } \\
\text { to change that decision. }\end{array}$ \\
\hline
\end{tabular}

The last version with these newly rephrased items, translated independently by 2 psychology specialists with high English proficiencies, has been approved by the supplier of the FACES IV Package. The present study focuses on FACES IV with those reformulated items.

\section{Psychometric Quality of FACES IV by Latent Class Analysis}

\section{Methods}

Statistical analyses were carried out using IBM SPSS 20 and Latent Gold 5.0 (Statistical Innovation Inc.) for Latent Class Analysis (LCA). LCA is a statistical method for identifying unmeasured class membership among subjects using categorical or continuous observed variables.

Internal consistency represented by Cronbach's alpha was measured to verify the reliability of the 6 scales (cohesion, flexibility, disengaged, enmeshed, rigid, chaotic) and the communication and satisfaction scales proposed by Olson.

LCA, which is most similar to the K-Means approach for cluster analysis and used by Olson, is a method for analyzing the relationships among polytomous manifest data when some variables are unobserved. The unobserved variables are categorical, allowing the original data set to be segmented into a number of latent classes (clusters). Individuals are classified into the class 
in which they have the highest posterior membership probability of belonging, given the set of responses (manifest variables) for that case. Advantages of Latent Class cluster models over more traditional ad-hoc types of cluster analysis methods include model selection criteria and probability-based classification. Posterior membership probabilities are estimated directly from the model parameters and used to assign cases to the modal class - the class for which the posterior probability is highest (Magidson and Vermunt, 2002).

For each subject, the raw scores were computed for the 6 Olson scales and then converted into 6 categorical variables conventionally known as cohesion, flexibility, disengaged, enmeshed, rigid, and chaotic according to the Olson algorithm and categories (or levels). The first 2 categories, cohesion and flexibility, were associated with the balanced scales and had the following 3 categories: 1, somewhat connected; 2, connected; and 3, very connected for cohesion and 1, somewhat flexible; 2, flexible; and 3, very flexible for flexibility. Each categorical variable was associated with the 4 unbalanced scales, disengaged, enmeshed, rigid, and chaotic, and were scored as follows: 1, very low; 2, low; 3, moderate; 4, high; and 5, very high.

Latent Class Analysis includes latent class factor models (DFactor Model) that identify factors, which group together variables sharing a common source of variation. The model may include several ordinal latent factors (Discrete Factors). The Discrete Factor (DFactor) model assumes that each factor contains 2 or more ordered categories as opposed to traditional factor analysis, which assumes that the factors (as well as the variables) are continuous (interval scaled) (Magidson and Vermunt, 2002).

Using the Olson methodology, the dimension scores on cohesion and flexibility for plotting scores on Circumplex Model have been computed. These dimension scores were created by using the balanced scores (for Cohesion or Flexibility) and adjusting the balanced scores up or down the scale based on whether the difference in the 2 unbalanced scales is at the high or low of the dimension using the following formulae:

cohesion $=$ balanced cohesion $+([$ enmeshed - disengaged $] / 2)$;

flexibility $=$ balanced flexibility $+([$ chaotic - rigid $] / 2)$

The percentile scores were used for each scale based on the raw scores as indicated in Olson methodology for FACES IV. The dimension score levels obtained were used to locate each person within the Circumplex Model. The model provided 25 types of family systems because each dimension has 5 levels. The following are the 5 levels of cohesion and flexibility that have been used with $20 \%$ for each level: $0-20,21-40,40-60,61-80$, and 81-100. The 9 balanced types are in the central area of the model, and there are 12 mid-range types balanced on 1 dimension and unbalanced on the other dimension. The 4 unbalanced types have unbalanced scores (very high or very low scores) on both cohesion and flexibility.

Using the Olson methodology, the ratio score of balanced and unbalanced scales was created for both cohesion (Cohesion Ratio) and flexibility (Flexibility Ratio) and the 2 scales combined (Circumplex Total Ratio). The 2 balanced scales measure the healthier family functioning and the 4 unbalanced scales measure the more problematic family functioning. As a result, the higher the ratio score of balanced to unbalanced, the healthier the family system. The higher the ratio score (above 1) is, the healthier the family system is and the lower the ratio (below 1) is, the unhealthier the family system is. Circumplex Total Ratio score was used to indicate the family's characteristics.

\section{Results}

The internal consistency was good for the 5 of 6 scales (Cronbach's alpha coefficient, ranging from .62 to .80). The consistency for the Chaotic scale was poor $(\alpha=.55)$ but still acceptable for this analysis. A very good internal consistency was observed for the Communication and Satisfaction scales (Table 3). 
Table 3. Reliability Statistics - Cronbach's alpha

\begin{tabular}{|l|c|}
\hline Subscale & Cronbach's alpha \\
\hline Cohesion & .80 \\
\hline Flexibility & .76 \\
\hline Disengaged & .69 \\
\hline Enmeshed & .62 \\
\hline Rigid & .69 \\
\hline Chaotic & .55 \\
\hline Communication & .91 \\
\hline Satisfaction & .94 \\
\hline
\end{tabular}

The LCA, LC Cluster Model best-fit statistics for latent class cluster models were estimated for all theoretical models with 1 to 8 latent classes. The best-fit model was selected considering the lowest Bayesian Information Criterion (BIC) value (9390.91) for the 6 clusters model with 55 parameters (Npar) and 546 degrees of freedom (df). The Consistent Akaike Information Criterion (CAIC) had also the lowest value for the 6 cluster model, CAIC=9445.91. For this particular model, the dissimilarity index was 0.69 , and the total bivariate residual BVR was 19.21. This large BVR value identified a correlation between the associated variable pairs (scales), which have not been adequately explained by the model (Table 4).

Table 4. LCA Best-fit Statistics

\begin{tabular}{|l|c|c|c|c|}
\hline \multicolumn{1}{|c|}{ Model } & BIC & CAIC & Npar & df \\
\hline 1-Cluster & 10454.69 & 10474.69 & 20 & 581 \\
\hline 2-Cluster & 9854.37 & 9881.37 & 27 & 574 \\
\hline 3-Cluster & 9607.37 & 9641.37 & 34 & 567 \\
\hline 4-Cluster & 9486.07 & 9527.07 & 41 & 560 \\
\hline 5-Cluster & 9418.57 & 9466.57 & 48 & 553 \\
\hline 6-Cluster & 9390.91 & 9445.91 & 55 & 546 \\
\hline 7-Cluster & 9397.22 & 9459.22 & 62 & 539 \\
\hline 8-Cluster & 9411.16 & 9490.70 & 69 & 532 \\
\hline 6-Cluster and 1 CFactor & 9342.45 & 9403.45 & 61 & 540 \\
\hline 6-Cluster with 1 CFactor and 1 covariate & 8318.14 & 8384.14 & 66 & 535 \\
\hline 2-DFactor (3.3) & 9353.78 & 9389.78 & 36 & 565 \\
\hline
\end{tabular}

Furthermore, the 6-class model was improved by including a class-independent continuous random intercept (CFactor 1) to capture respondent differences in average attitude across all scales and latent classes. The CFactor was considered as a reflection of individual liability on an assumed continuous latent trait, as it is explained in item response theory (IRT) models. As a confirmation of the model improvement, the BIC value decreased to 9342.45 , and the total BVR dropped to 1.97. CAIC also decreased to 9403.45.

For improved cluster or segment description (and prediction), the relationships between the latent classes and external variables (covariates) were assessed simultaneously with the 
identification of the classes (clusters, segments). This eliminated the need for the usual second stage of analysis where a discriminant analysis is performed to relate the resulting clusters or factors obtained from a traditional cluster or factor analysis to demographic and other variables.

For the purpose of this research, the computed Circumplex Total Ratio was used as a numeric covariate to assess the family health for each cluster. For the model with covariates, the BIC value decreased to 8318.14 and CAIC decreased to 8384.14. Classification statistics, such as Lambda Reduction of errors (0.89) and Entropy $\mathrm{R}^{2}(0.87)$, being over 0.8 , indicated that reasonable accurately, respondents can be assigned to the classes. Over $5 \%$ of cases were present for each cluster. This assured meaningfulness of the model, as small size clusters add no value, except in very obscure edge conditions.

Each cluster was associated with a family profile defined by the profile scores provided by the Latent Gold profile output as class-specific means. For the family profiles presented in Figure 1, the 0-1 means for each Olson scale are plotted on the vertical axis instead of classspecific means.

The advantage of such scaling is that these numbers can be depicted on the same scales that always lie within the 0 to 1 range for all categorical variables. Scaling these " 0 to 1 means" was accomplished by subtracting the lowest observed value from the class-specific means and dividing the results by range, which was simply the difference between the highest and the lowest observed category values. On the same graphical representation, a reference profile was also plotted.

The reference profile scores (AVERAGE) were computed as the mean of the 6 classes for each scale. Latent Gold software provided the means, after model estimation, to assign individuals to latent classes or clusters using their posterior class membership probabilities and, subsequently, investigated the association between the assigned class memberships and external variables. Class assignment can be modal (to the class for which the posterior membership probability is largest) or proportional (to each class with a weight equal to the posterior membership probability for that class).

Figure 1. Family profiles - 6 clusters, 1 CFactor, and 1 covariate Circumplex total ratio

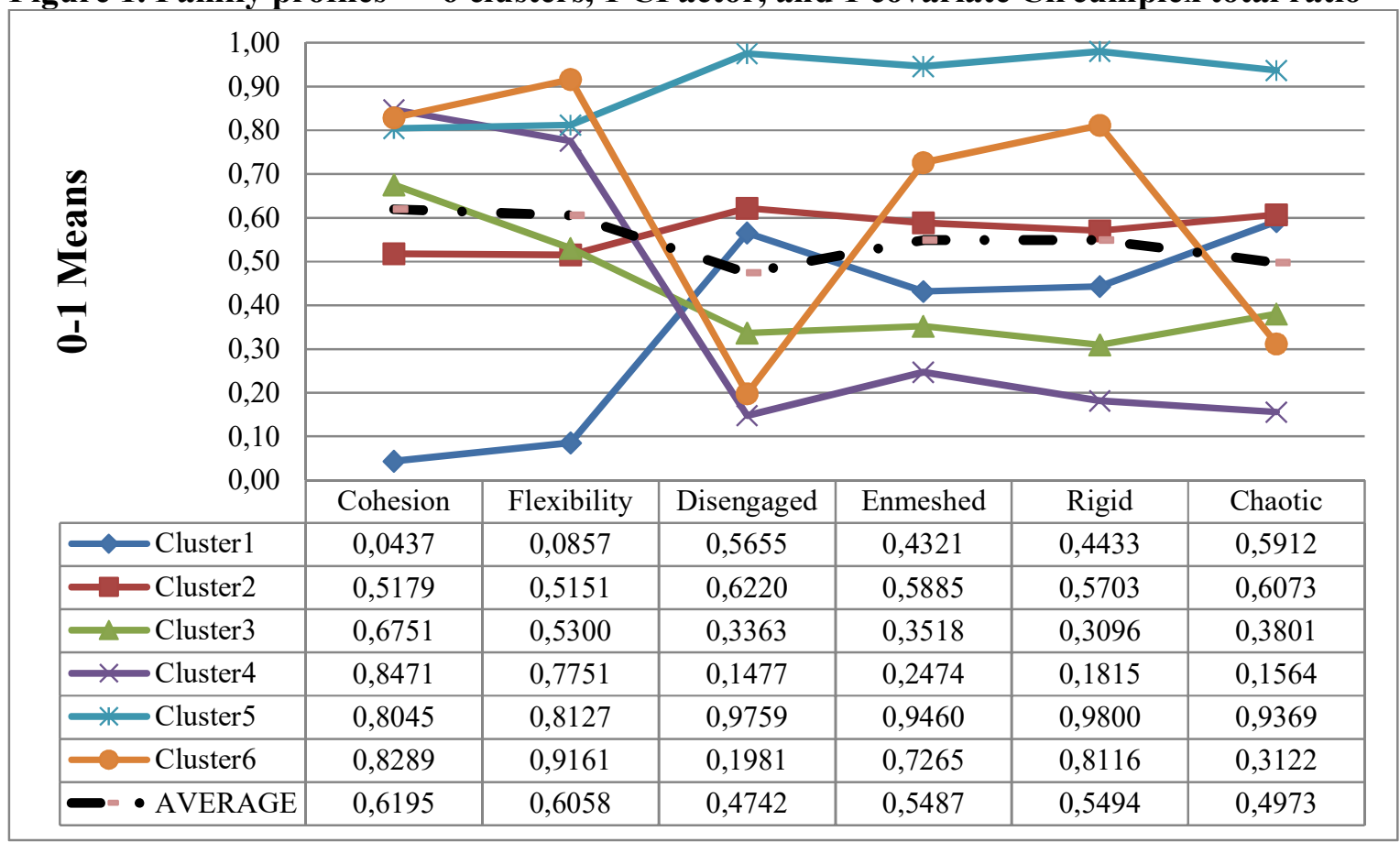


Cluster 1 was the largest cluster and represented $27 \%$ of the sample population. This cluster was characterized by low scores on the cohesion and flexibility balanced subscales and high scores on the unbalanced subscales, disengaged, enmeshed, rigid, and chaotic. The average covariate Circumplex Total Ratio was very low (.36). This profile was considered to be similar to the Unbalanced family profile described by Olson. After posterior classification, the cluster proportion was still $27 \%$. The posterior probabilities in Latent Class Analysis (LCA) refer to the probability of that observation that is classified in a given class.

Cluster 2 represented almost $26.6 \%$ of the sample population. Moderate scores on the balanced and unbalanced subscales characterized this cluster. The average covariate Circumplex Total Ratio was .91. This profile was considered to be similar to the Midrange family profile described by Olson. After posterior classification, the cluster proportion was $26.3 \%$.

Cluster 3 represented almost $14.9 \%$ of the sample population. This cluster was characterized by low scores on the unbalanced 4 scales (disengaged, enmeshed, rigid, and chaotic). However, this cluster was characterized also by high to moderate scores on the Cohesion and Flexibility scales. The average Circumplex total ratio was 1.66 , indicating a healthy family system. This profile was considered to be similar to the Moderate Balanced family profile described by Olson. After posterior classification, the cluster proportion was $15.5 \%$.

Cluster 4 represented almost $14.9 \%$ of the sample population. This cluster was characterized by high scores on flexibility and cohesion. The scores on the unbalanced subscales were low especially on disengaged and chaotic. The average covariate Circumplex Total Ratio was very high (4.34), indicating a very healthy family system. This profile was considered to be similar to the Balanced family profile described by Olson. After posterior classification the cluster proportion was $15.0 \%$.

Cluster 5 represented almost $9.8 \%$ of the sample population. This cluster was characterized by high scores on flexibility and cohesion. The scores on the unbalanced subscales disengaged, enmeshed, rigid, and chaotic were also high and uniform, almost equal. The average covariate Circumplex Total Ratio was .85 . This profile is in the category of Midrange family profile, translated in parallel with the high score space. The cluster was also suspected to be an Extreme Response Style (ERS) segment that included the respondents with systematic tendency to choose categories on Likert scales, independent of the intended object of measure. ERS is the tendency to choose only the extreme endpoints of the scale. After posterior classification, the cluster proportion was $10.1 \%$.

Cluster 6 represented almost $6.6 \%$ of the sample population. This cluster was characterized by high scores on flexibility and cohesion. The scores on the unbalanced subscales were high on enmeshed and rigid and very low on disengaged and chaotic. The average covariate Circumplex Total Ratio in the cluster was 1.56, indicating a healthy balanced family system. With some differences regarding unbalanced scores, this profile was considered to be similar to the Rigidly Cohesive family profile described by Olson. After posterior classification, the cluster proportion was $6.2 \%$.

The classic LCA model with covariate is summarized as follows: $36.6 \%$ of the sample population as balanced, $36.4 \%$ as midrange, and $27.9 \%$ as unbalanced.

For the purpose of this research, a DFactor Model with 2 discrete factors was also estimated. The best-fit model was selected considering the lowest BIC value (9353.91) for the 3 levels (1, low; 2, medium; 3, high) in each DFactor, with 36 parameters (Npar) and 565 degrees of freedom (df). For this particular model, the dissimilarity index was 0.71 , and the total bivariate residual BVR was 9.69. The CAIC value was 9389.78.

Inspection of the model loadings indicated that Cohesion and Flexibility load primarily on DFactor1, whereas disengaged, enmeshed, rigid, and chaotic load on DFactor2. In addition, the Latent Gold software bi-plot of the results in graphical presentation, as in Correspondence 
Analysis, helped to interpret the abovementioned DFactors. Each indicator variable category was positioned in a 2-dimensional space at a point where coordinates are aggregated mean DFactor scores obtained for all cases responding in this category.

For more clarity, curved lines connecting the categories of a variable have been added. The graphical presentation indicated that cohesion and flexibility discriminate over DFactor 1 (balance) axis, whereas disengaged, enmeshed, rigid, and chaotic were associated with the DFactor2 (unbalanced) axis. This was a confirmation of Olson family classification theory, regarding balance and unbalance characteristics of family type.

Figure 2. DFactor (3.3) Model, biplot of results with curved lines connecting the categories of a variable

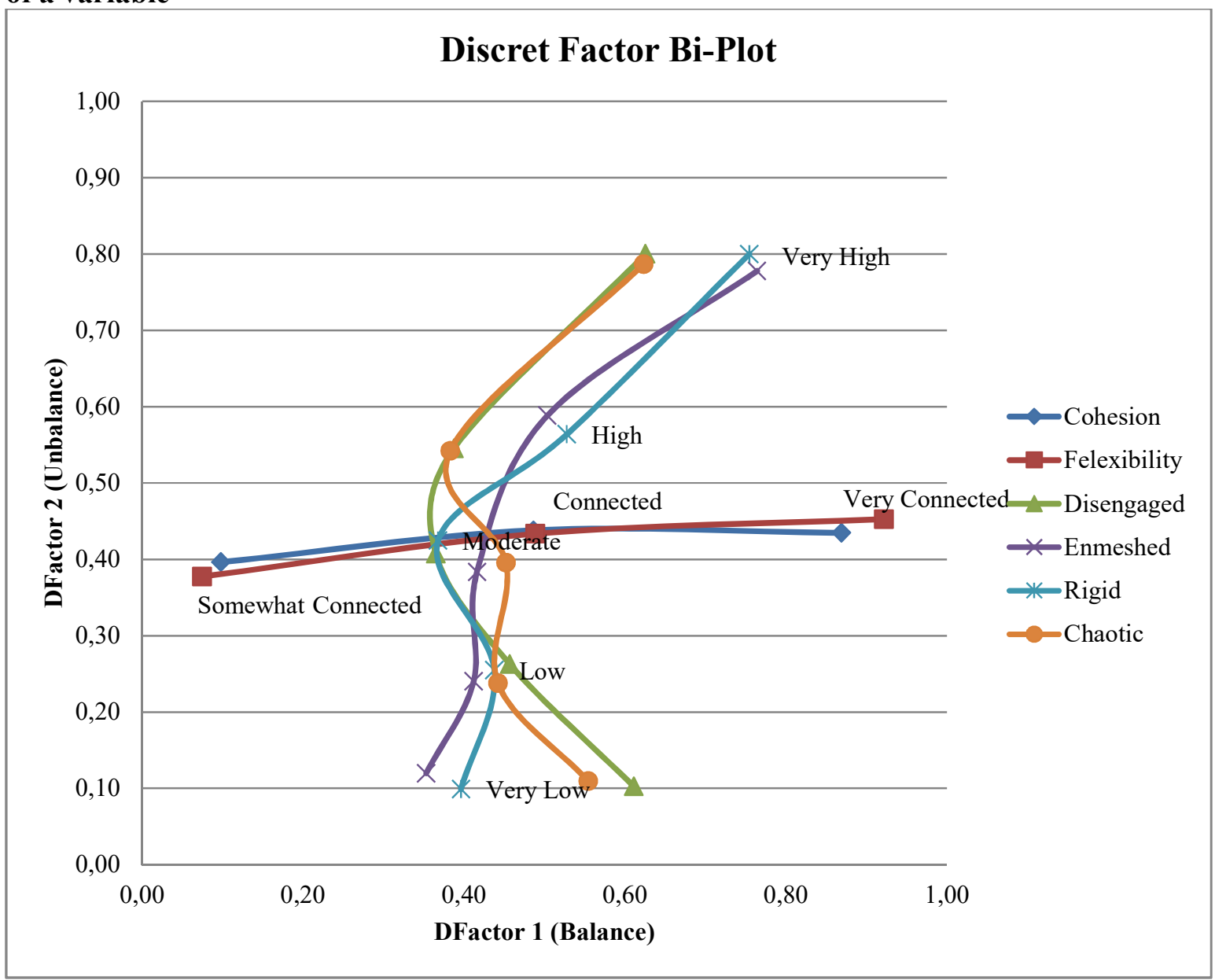

\section{Plotting on Circumplex Model of the Cohesion Dimension and Flexibility Dimension Scores and the Influence of the Sociodemographic Characteristics}

The distribution in the sample by type of family system is shown in Figure 3. 


\section{Figure 3. Family flexibility and cohesion among people older than 55 years from Romania according to the FACES IV}

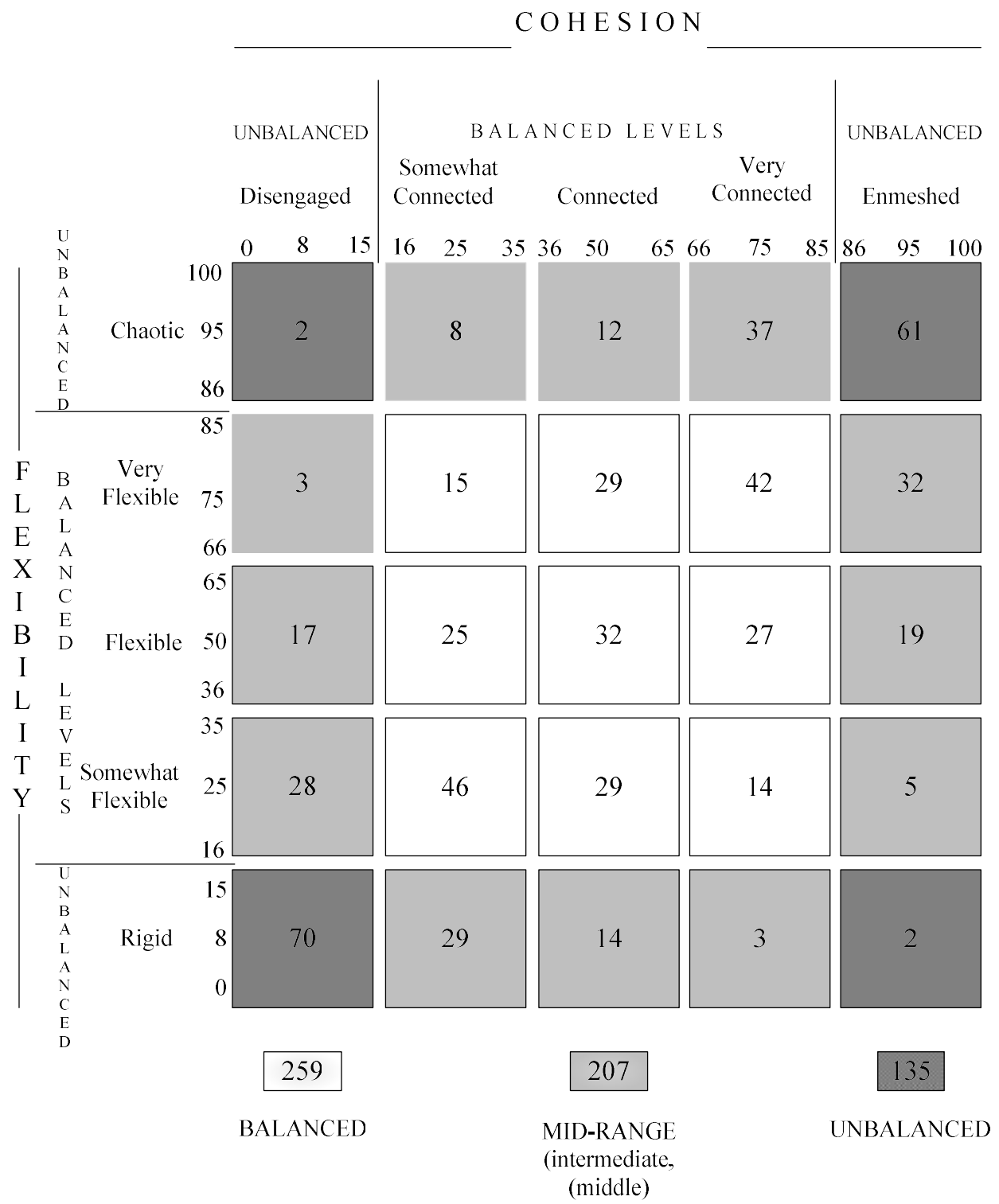

Figure 3 reveals the fact that Balanced functioning family system prevails, with the following predominant types of families: somewhat connected-somewhat flexible and very connected-very flexible. Within Unbalanced functioning family system, the rigid-disengaged and chaotic enmeshed types of families prevail, whereas the types chaotic-disengaged and rigidenmeshed are less represented.

The Pearson Chi-Square showed that in the sample studied there was a statistically significant difference in Circumplex Total Ratio score between the different residence places, $(\chi 2=4.957, \mathrm{df}=1, \mathrm{p} 0.026)$, the share of the unhealthy family system being higher in the rural area was $60.9 \%$ compared with the urban environment with $50.6 \%$. No significant differences in Circumplex Total Ratio scores between genders and age groups were observed 


\section{Discussions}

The fact that in the evaluation through the Cronbach's alpha coefficient, the removal of any item from the Chaotic scale did not lead to the increase of consistency is probably caused by the lack of adaptability of these scale items to the Romanian culture.

Compared with the internal consistency obtained through the application of FACES IV to young adults (18-30 years), the internal consistency obtained in this study in the adult and elderly population (55-93 years) was maintained or increased at all scales except for the disengaged scale, where it declined, although no item from this scale was reformulated. Although as concerns flexibility, 6 of 7 items of the rigid scale and 4 of 7 items of the balanced flexibility scale were reformulated, only a 2-point increase in the consistency of the chaotic scale was obtained. The chaotic scale remains empirically weaker. With regard to the chaotic scale, it results that Flexibility dimension which gives the profile of the Chaotic scale relates rather to the role distribution, to the management, and less to the organization; for example, the answers The strongest disagreement registered the highest share for the item "We never seem to get organized in our family."

Like Olson's study which indicated in 20086 types of families, the present study identified also 6 types of families or clusters that were improved by including a classindependent continuous random intercept to capture respondent differences in average attitude across all scales and latent classes. Circumplex Total Ratio was used as a numeric covariate to assess the family health for each cluster. The latent class factor models (DFactor Model) indicated that the 6 subscales discriminate in 2 discrete factors orthogonal space: balance and unbalance. The findings of this research are somehow different with those presented in the Italian Faces IV study in 2013, among Italian adolescents (Baiocco et al., 2013) when 5 types of families have been identified.

The fact that about three fourths of the subjects described the family so that it belongs to the balanced and midrange categories indicates that the Romanians from the sample studied have a good potential of intimacy and adaptability and healthy family functioning methods.

Taking into account the Circumplex Total Ratio, the subjects in the urban area have described the family system as healthier than those in the rural area. This is an aspect that should be better explored through interviews.

The fact that in this sample there were no significant statistical differences on gender, age groups, place of residence in terms of cohesion and flexibility scales can be explained by a tendency to homogenize the actors within the family in the modern and post-modern period as a result of the emancipation of women, the interchangeable roles in the couple, and the migration that allows the borrowing of models from other cultures (Rada, 2013).

In comparison with other studies in which the dynamics of the couple as regard control and cooperation was expressed relatively differently between men and women and between the middle-aged couples and older couples (Smith et al., 2009); in the current study, these variables did not greatly influence the scores on any of the 6 scales of flexibility and cohesion.

Moreover, as years pass, rather, as the years of marriage pass, the couples become more stable, with less power struggle and competition within the couple. Like other studies (Rada and Pănescu, 2016), the current research reveals, through the high share of the families of balanced and midrange types, that toward the end of the middle age and beginning with the third age, the partners mutually understand and respect their attachment needs and are more aware of their major role as sources of support and caring for each other.

In the case of the elderly, the challenges of the couple consist of the decrease of the mental and psychical health potential which makes the marital obligations more difficult to manage (Iveniuk et al., 2014). Even if the subjects in the studied sample were diagnosed with at least 1 chronic illness, the family functioning as regard the 2 dimensions - flexibility and 
cohesion - was mostly balanced. The elderly in this sample have understood, like those in other studies (Berg et al., 2007), that collaboration regarding the domestic chores and spending time together after the retirement are an important resource for well-being.

Some dysfunctions are determined by the occurrence of some gaps between the partners' needs. The fact that the sample is formed of subjects who were not in a family crisis can explain the low share of the families of unbalanced type.

\section{Conclusions}

Like any authors, we consider that FACES IV is, in general, a good instrument, and the differences in strengths and internal consistency derive from the aspects connected to the cultural space (Martínez-Pampliega et al., 2017).

Values Cronbach's alpha over 0.90 of Family Communication and Family Satisfaction scales, in the previous study conducted on people between 18-30 years and in the present study conducted on people between 55-93 years, show that they are good tools in the Romanian context.

In exploratory studies, a 0.60 value of Cronbach's alpha can be accepted (Garson, 2010; Popa, 2011). Internal consistency close to 0.7 and even higher in all the scales except for the Chaotic scale shows that FACES IV can be a useful instrument in the Romanian context. A different approach regarding the Chaotic concept in the Romanian ex-Communist cultural space could explain the low power of this scale.

The Communist regime in Romania, which ended in 1989, violated the rights to freedom, food, decent living conditions, and so on. The Party and the State controlled the public and private lives. The father dominated the family. The promotion and the career of a person could be affected by a divorce or a marriage if that was considered inappropriate from the point of view of political affiliation, partner, political past, relations with foreign countries, and even parents. Deviations in this sense were sanctioned. Under these circumstances, where education and family and social roles were rigid, it is possible that the meaning given by the subjects to flexibility could be influenced by this background.

The subjects' answers to the flexibility scale, the interpretation of the chaotic concept could be a result of the gained freedom, an interpretation of this freedom as a chaos.

To overcome this impediment, it would be a good idea to clarify the meaning of the term chaotic through an interview or an open question.

However, using the Latent Class Analysis with categorical variables, the exploratory analysis has been obtained in a model with 6 clusters, as statistically best fit. The model, which is comparable, with some differences, with the family profiles structures described by Olson, indicated that FACES IV was confirmed to be a reliable approach.

The study of subjects older than 55 years from non-clinical families (were not under family psychotherapy) highlights family profiles showing homogeneous flexibility and cohesion by gender, age group, and residence. It is the result of several age-related events, such as the decrease of professional and social identity, the marriage of children, the birth of grandchildren recharging with privacy in another context the marital and parental identity; then retirement that changes the family budget, the family schedule, the interests, and the social relationships. The biological and psychological regression, the health issues, the low income - the main problems of the elderly - require the decrease of the competitive interactive model, a good manifestation of adaptability, cohesion, and of the model of cooperation as mechanisms coping with these challenges.

A merit of this article is that it evaluates the validity using a different method (LCA) with 2 models: clusters and discrete factors. Another merit of this article is to reveal FACES IV 
value in longitudinal and transversal research on changes within the family as a system, within family life cycles, in the context of changes in legislative, economic contexts, and so on.

\section{Limitations}

The main limit of this study is that it was done on families who were not under psychotherapy. Another limit is the fact that the study was not effective on couples so that the perception of each partner of the marital pair could be identified and compared.

\section{Ethical considerations}

Informed written consent was obtained from each participant at the time of recruitment. The subjects were informed that they could withdraw from the study at any stage, and confidentiality was assured. The study was approved by the Ethics Commission of "Francisc I. Rainer" Anthropology Institute of the Romanian Academy (153/01-03-2016).

\section{Acknowledgments}

The data used for this article were sourced on Quantitative and Qualitative Study on Successful Aging. A Psycho-Socio-Medical Approach on Third Age project made by the "Francisc I. Rainer" Anthropology Institute of the Romanian Academy (691/12.08.2015) and "Ana Aslan" National Institute of Gerontology and Geriatrics (10413/01.09.2015) from Bucharest. The topic was approved by the Scientific Council of "Francisc I. Rainer" Anthropology Institute of the Romanian Academy with 1021/04-11-2015. Project managers Rada C., Draghici R. Participants: Ispas A.T., Baciu A.B., Prada G.I., Pena C., Vârtan I., Stan P., Lazăr C.

I would like to express my gratitude to all the people involved in this research. I am especially grateful to Professor David Olson for guidance.

\section{Funding}

This study did not receive any direct funding.

\section{Bibliography}

1. Baiocco, R., Cacioppo, M., Laghi, F. and Tafà, M., 2013. Factorial and construct validity of FACES IV among Italian adolescents. Journal of Child and Family Studies, [e-journal] 22, pp.962-970, https://doi.org/10.1007/s10826-012-9658-1.

2. Berg, C.A., Smith, T.W., Ko, K.J., Henry, N.J.M., Florsheim, P., Pearce, G., Uchino, B., N., Skinner, M.A., Beveridge, R.M., Story, N. and Glazer, K., 2007.Task control and cognitive abilities of self and spouse in collaboration in middle-aged and older couples. Psychology and Aging, 22, pp.420-427.

3. Carvalho, J.C., Freitas, P.P., Leuschner, A. and Olson, D.H., 2014. Healthy functioning in families with a schizophrenic parent. Journal of Family Psychotherapy, [e-journal] 25, pp.111, https://doi.org/10.1080/08975353.2014.881685.

4. Di Nuovo, S., Loriedo, C. and Visani, E., 2013. FACES-IV reliability and validity in an adult Italian sample. Technical Report, doi:10.13140/2.1.1866.1447.

5. Garson, D., 2010.Statnotes: Topics in multivariate analysis - Reliability analysis. [online] Available at: $<\underline{\text { http://faculty.chass.ncsu.edu/garson/PA765/reliab.htm }>[A c c e s s e d ~} 8$ August 2017]. 
6. Hugo, M.S.G., Peixoto, F. and Gouveia-Pereira, M., 2017. Portuguese validation of the family adaptability and cohesion evaluation scale - FACES IV, [online] Available at: $<$ https://doi.org/10.1080/13229400.2017.1386121> [Accessed 8 August 2017].

7. Iveniuk, J., Waite, L., Laumann, E.K., McClintock, M. and Tiedt, A., 2014. Marital conflict in older couples: positivity, personality, and health. Journal of Marriage and Family, [ejournal] 76(1), pp.130-144. https://doi.org/10.1111/jomf.12085.

8. Koutra, K., Triliva, S., Roumeliotaki, T., Lionis, C. and Vgontzas, A.N., 2013. Crosscultural adaptation and validation of the Greek version of the Family Adaptability and Cohesion Evaluation Scales IV package (FACES IV package). Journal of Family Issues, [ejournal] 34, pp.1647-1672. https://doi.org/10.1177/0192513X12462818.

9. Loriedo, C., Visani, E. and Di Nuovo, S., 2017. FACES-IV standardization in an adult italian sample - updating 2017, [online] Available at:

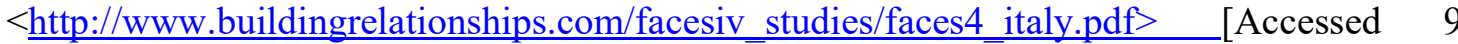
August 2017].

10. Magidson, J. and Vermunt, J. K., 2002. Latent class models for clustering: A comparison with K-means. Canadian Journal of Marketing Research, 20, pp.37-44.

11. Margasiński, A., 2014. An outcome study of alcoholic families in Poland using FACES IV. Journal of Family Psychotherapy, [e-journal] 25, pp. 348-358, https://doi.org/10.1080/08975353.2014.977684.

12. Marsac, M.L. and Alderfer, M.A., 2011. Psychometric properties of the FACES-IV in a pediatric oncology population. $J$ Pediatr Psychol, [e-journal] 36, pp. 528-538. https://doi.org/10.1093/jpepsy/jsq003.

13. Martínez-Pampliega, A., Merino, L., Iriarte, L. and Olson, D.H., 2017. Psychometric Properties of the Spanish version of the Family Adaptability and Cohesion Evaluation Scale IV. Psicothema, [e-journal] 29(3), pp.414-420. https://doi.org/10.7334/psicothema2016.21.

14. Mirnics, Z., Vargha, A., Tòth, M. and Bagdy, E., 2010. Cross-cultural applicability of faces IV. Journal of Family Psychotherapy, [e-journal] 21, pp. 17-33. https://doi.org/10.1080/08975351003618577.

15. Olson, D.H., Sprenkle, D.H. and Russell, C.S., 1979. Circumplex model of marital and family system: I. Cohesion and adaptability dimensions, family types, and clinical applications. Family Process, [e-journal] 18, pp.3-28. https://doi.org/10.1111/j.15455300.1979.00003.x.

16. Olson, D.H. and Gorall, D.M., 2006. FACES IV \& the Circumplex Model. [online] Available at: $<$ https://www.societyofpediatricpsychology.org/sites/default/files/files/3_innovations.pdf $>$ [Accessed 9 August 2017].

17. Olson, D.H., 2010a. FACES IV Manual. Minneapolis, MN: Life Innovations.

18. Olson, D.H., 2010b. Guidelines for translating FACES IV package. [online] Available at:

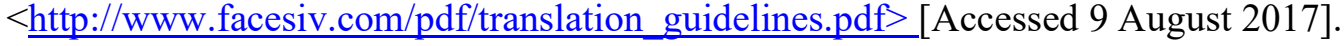

19. Olson, D.H., 2011. FACES IV and the circumplex model: Validation study. Journal of Marital and Family Therapy, 37(1), pp. 64-80.

20. Popa, M., 2011. "Infidelitățile” coeficientului de fidelitate Cronbach alfa. („Infidelities” of Cronbach alpha fidelity). Psihologia resurselor Umane, 9 (1), pp.85-99.

21. Rada, C., 2013. Valori identitare ale familiei româneşti contemporane în contextul globalizării. O abordare antropologică, (Identitary Values of the Contemporary Romanian Family in the Framework of the Globalization. An Anthropological Approach) Bucureşti: Editura Muzeului Național al Literaturii Române, Colecția AULA MAGNA, (with an English Summary, pp.324-354, [online] Available at:

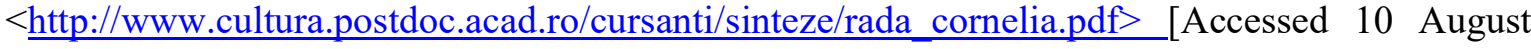
2017]. 
22. Rada, C., 2018. Latent Class Analysis Approach for the Family Adaptability and Cohesion Evaluation Scale IV Among Young People From Romania: The First Step for Validation, Journal of Family Issues, [e-journal] 39(6), pp. 1598-1615. https://doi.org/10.1177/0192513X17714508.

23. Rada, C. and Olson, D.H., 2016. Circumplex Model of Marital and Family Systems (Faces III) in Romania, Annuaire Roumain D'anthropologie, Bucharest: Editura Academiei Române, 53, pp.11-29.

24. Rada, C. and Pănescu, O.M., 2016. Psihologia, psihoterapia familiei şi cuplului. Teorii, cercetări, intervenţii (Psychology, psychotherapy of family and couples. Theories, research, interventions), Bucureşti: Editura Universitară.

25. Rivero, N., Martinez-Pampliega, A. and Olson, D.H., 2010. Spanish adaptation of the FACES IV questionnaire: Psychometric characteristics. Family Journal, [e-journal] 18, pp. 288-296. http://dx.doi.org/10.1177/0192513x1771.4508

26. Smith, T.W., Berg, C.A., Florsheim, P., Uchino, B.N., Pearce, G., Hawkins, M., Henry, N.J.M., Beveridge, R.M., Skinner, M.A. and Olsen-Cerny, C., 2009. Conflict and Collaboration in Middle-Aged and Older Couples: I: Age Differences in Agency and Communion during Marital Interaction. Psychology and Aging, [e-journal] 24(2), pp. 259273. http://doi.org/10.1037/a0015609.

27. Visani, E., Loriedo, C., Di Nuovo, S., Menichincheri, R., Seravelli, F., Agostino, C. and Ferrara, C., 2017.Clinical versus Normal Italian Families using FACES IV, [online] Available

at:

$<$ http://www.buildingrelationships.com/facesiv_studies/faces4 italy clinical.pdf $>$ [Accessed 4 September 2017]. 